\title{
ANALISIS DAMPAK MARKETING MIX DAN PROTOKOL KESEHATAN TERHADAP KEPUTUSAN MENGINAP PADA SAAT PANDEMI COVID-19 (STUDI KASUS DI HOTEL ROYAL JEMBER)
}

\author{
Hadi Jatmiko ${ }^{1}$, Faozen ${ }^{2}$ \\ Universitas Muhammadiyah Jember, Indonesia \\ Email : hadijatmiko@unmuhjember.ac.id
}

\begin{abstract}
Abstrak
Pembahasan penelitiaan ini dititikberatkan pada Analisis Dampak Marketing Mix Dan Protokol Kesehatan Terhadap Keputusan Menginap (Studi Kasus Di Hotel Royal Jember). Harapannya hasil penelitian ini dapat memberikan masukan kepada pengelola hotel di Jember khususnya dalam mengambil kebijakan dan strategi pemasaran yang tepat pada masa pandemi covid-19. Tujuan pnelitian ini adalah menganalisis dampak marketing mix dan protokol kesehatan terhadap keputusan tamu menginap di hotel pada saat pandemi Covid-19 (Studi Kasus Di Hotel Royal Jember. Populasi diambil dari tamu yang menginap di Hotel Royal Jember dengan responden berjumlah 31 responden. Hasil Penelitian menunjukkan bahwa, (1) Promosi, Fasilitas, Lokasi, Protokol kesehatan berpengaruh signifikan terhadap keputusan menginap di Hotel Royal Jember.; (2). Harga tidak berpengaruh signifikan terhadap keputusan menginap di Hotel Royal Jember.; (3) Fasilitas berpengaruh dominan terhadap keputusan menginap di Hotel Royal Jember.
\end{abstract}

Kata Kunci : Marketing Mix, Keputusan Menginap , Pandemi Covid-19

\begin{abstract}
The research focus discusses the Analysis of the Impact of Marketing Mix and Health Protocols on the Decision to Stay (Case Study at Hotel Royal Jember). It is hoped that the results of this research can provide input to hotel managers in Jember, especially in making the right policies and marketing strategies during the Covid-19 pandemic. The purpose of this research is to analyze the impact of marketing mix and health protocols on guest decisions to stay at hotels during the Covid-19 pandemic (Case Study at Hotel Royal Jember. Population is taken from guests staying at Hotel Royal Jember with 31 respondents. Result of the research and discussion show that, (1) Promotion, facilities, location, health protocols have a significant effect on the decision to stay at the Hotel Royal Jember .; (2) Price does not have a significant effect on the decision to stay at the hotel. Royal Jember .; (3) Facilities have a dominant effect on the decision to stay at Hotel Royal Jember
\end{abstract}

Keywords: Marketing Mix, Decision to Stay, Pandemi Covid-19 


\section{PENDAHULUAN}

Hampir seluruh sektor usaha, baik barang dan jasa terdampak oleh pandemi covid-19 saat ini, salah satu sektor itu adalah usaha sektor jasa perhotelan. Kondisi ketidak pastian dan maraknya pembatasan oleh Pemerintah menjadikan jumlah konsumen atau kunjungan hotel mengalami penurunan yang signifikan.

Pengelola hotel di Jember berupaya untuk dapat mengembalikan tingkat kunjungan tamu meski pandemi covid-19 masih berlangsung, salah satunya Royal Hotel n' Lounge Jember dengan strateginya dalam hal ini sebagai tempat studi penelitian.

Keputusan pembelian adalah tindakan dari konsumen untuk mau membeli atau tidak terhadap sebuah produk atau jasa (Kotler, 2002). Perusahaan harus dapat menerapkan strategi yang baik agar konsumen bisa tertarik untuk membeli produk atau jasanya, sehingga dapat memudahkan perusahaan untuk memenangkan persaingan.

Baunsele, Kasim, Bessie (2016) memaparkan dalam hasil penelitiannya bahwa promosi, fasilitas, lokasi dan harga secara simultan mempunyai pengaruh signifikan terhadap keputusan menginap.

Pandemi mengakibatkan perilaku tamu dalam menentukan menginap di hotel, para tamu akam memilih hotel yang benar - benar aman dan nyaman pada saat pandemi, bahkan ada keraguan tamu untuk memutuskan menginap. Sehingga mempengaruhi tingkat keterisian kamar yang setiap hotel di Jember, termasuk hotel Royal Jember.

Pengelola bisnis perhotelan yang terdampak pandemi ini harus menyusun strategi dalam rangka mengembalikan kepercayaan pengunjung dengan mengetahui perilaku pengunjung saat pandemi Covid-19, sehingga dapat menyusun kebutuhan tamu sesuai dengan perilakunya saat pandemi saat ini.
Marketing Mix dan protokol kesehatan dapat dijadikan program bagi hotel untuk menemukan strategi dan kebijakan yang tepat agar menjaga tamu tetap memutuskan menginap di hotel.

\section{METODOLOGI}

Teknik pengumpulan datanya menggunakan wawancara terstruktur dengan penelola hotel dan tamu yang sedang menginap dengan kuesioner sebanyak 31 responden sebagai data primer, dengan menggunakan teknik analisis data Regresi Linier Berganda dan Pengujian Terhadap Hipotesis Penelitian yang bertujuan untuk menguji signifikansi sebagai dasar membahas hasil penelitian.

\section{HASIL DAN PEMBAHASAN}

Berikut hasil yang dapat disajikan dari uji analisis data :

Tabel 1. Hasil Perhitungan Regresi Linear Berganda

\begin{tabular}{|l|c|c|c|c|}
\hline \multicolumn{1}{|c|}{ Variabel } & Koef. Regresi & thitug & Sig. & Keterangan \\
\hline Konstanta & $-0,102$ & $-0,090$ & 0,929 & - \\
X1 & 0,198 & 3,226 & 0,003 & Signifikan \\
X2 & 0,274 & 3,723 & 0,001 & Signifikan \\
X3 & 0,111 & 2,101 & 0,046 & Signifikan \\
X4 & 0,125 & 1,356 & 0,187 & Tidak Signifikan \\
X5 & 0,138 & 2,311 & 0,029 & Signifikan \\
\hline
\end{tabular}

Berdasar tabel diatas, dapat dibuat persamaan :

$$
Y=-0,102+0,198 X_{1}+0,274 X_{2}+
$$

$0,111 \mathrm{X}_{3}+0,125 \mathrm{X}_{4}+0,138 \mathrm{X}_{5}+\mathrm{e}$

Adapun penjelasannya adalah :

1. Konstanta sebesar -0,102, menunjukkan besanya keputusan menginap pada saat variabel promosi, fasilitas, lokasi, harga, dan protokol kesehatan sama dengan nol. Keputusan menginap akan terjadi penurunan tanpa kelima variabel tersebut yang disebabkan oleh faktor lain. 
2. $\mathrm{b}_{1}=0,198$, artinya apabila variabel fasilitas, lokasi, harga, dan protokol kesehatan sama dengan nol, maka peningkatan variabel promosi akan meningkatkan keputusan menginap.

3. $\mathrm{b}_{2}=0,274$ artinya apabila variabel promosi, lokasi, harga, dan protokol kesehatan, sama dengan nol, maka peningkatan variabel fasilitas akan meningkatkan keputusan menginap.

4. $b_{3}=0,111$, artinya apabila variabel fasilitas, promosi, harga, dan protokol kesehatan sama dengan nol, maka peningkatan variabel lokasi akan meningkatkan keputusan menginap.

5. $\mathrm{b}_{4}=0,125$ artinya apabila variabel promosi, lokasi, fasilitas, dan protokol kesehatan, sama dengan nol, maka peningkatan variabel harga akan meningkatkan keputusan menginap.

6. $\mathrm{b}_{5}=0,138$ artinya apabila variabel promosi, fasilitas, lokasi, dan harga sama dengan nol, maka peningkatan variabel protokol kesehatan akan meningkatkan keputusan menginap.

Berikut hasil pengujian variabel independen yang dominan :

Tabel 2, Nilai Standarized Coeffisient Beta

\begin{tabular}{|l|c|c|c|}
\hline Variabel & Koef. Regresi & thitus & Sig. \\
\hline X1 & 0,244 & 3,226 & 0,003 \\
X2 & 0,347 & 3,723 & 0,001 \\
X3 & 0,210 & 2,101 & 0,046 \\
X4 & 0,140 & 1,356 & 0,187 \\
X5 & 0,277 & 2,311 & 0,029 \\
\hline
\end{tabular}

Berdasarkan Nilai Standarized Coeffisient Beta dapat dinyatakan bahwa diantara variabel independen yang terdiri dari promosi, fasilitas, lokasi, harga, dan protokol kesehatan yang memiliki pengaruh dominan terhdap variabel dependen (keputusan menginap) adalah varibel fasilitas $\left(\mathrm{X}_{2}\right)$. Sehingga dapat dinyatakan terkait dengan pertanyaan faktor yang memberikan dampak yang terbesar (dominan) terhadap Keputusan Menginap Di Hotel Pada Saat Pandemi Covid-19 adalah faktor fasilitas.
Setelah dilakukan pengujian statistik, hasil dan pembahasan penelitian ini adalah :

1. Pengaruh Promosi terhadap Keputusan Menginap.

Variabel promosi berpengaruh positif dan signifikan terhadap keputusan menginap. Hal ini berarti faktor promosi yang diukur melalui Iklan Hotel baik melalui media cetak maupun media elektronik (surat kabar, radio, dan internet) dinilai menarik dan inovatif, Hotel menggunakan alat atau barang promosi dan souvenir (brosur, poster, pulpen, dan lainnya) yang dinilai menarik dan informative serta dapat dipercaya dimana ada keseuaian produk dan jasa yang ditawarkan.

2. Pengaruh Fasilitas terhadap Keputusan Menginap.

Variabel fasilitas berpengaruh positif dan signifikan terhadap keputusan menginap. Hal ini menunjukkan bahwa tersedianya fasilitas layak dan berkualitas.

3. Pengaruh Lokasi terhadap Keputusan Menginap.

Variabel lokasi berpengaruh positif dan signifikan terhadap keputusan menginap. Hal ini berarti faktor lokasi yang diukur melalui letak hotel mudah dijangkau karena tersedia jalan yang baik, lokasi hotel berada di lingkungan yang nyaman, dan lalu lintas di sekitar area jalan hotel tergolong tertib.

4. Pengaruh Harga terhadap Keputusan Menginap.

Variabel harga berpengaruh positif namun tidak signifikan terhadap keputusan menginap. Hal ini menunjukkan bahwa harga yang tertera sesuai dengan fasilitas yang disediakan, harga yang tertera oleh hotel dinilai mampu bersaing dengan harga yang ditawarkan oleh hotel lain, dan hotel cukup sering menawarkan kebijakan atau 
promosi potongan harga bukan merupakan suatu faktor yang menentukan keputusan menginap di Hotel Royal Jember. Dalam hal ini, faktor harga menjadi faktor yang kurang diperhatikan oleh konsumen dalam memutuskan untuk menginap di hotel. Hal ini bisa dijelaskan bahwa harga secara umum untuk hotel sudah standar atau relatif sama pada semua hotel dengan kelas yang sejenis, dan konsumen yang menggunakan jasa menginap di hotel pada umumnya merupakan konsumen kelas menengah atas, sehingga harga sudah tidak menjadi fokus utama.

5. Pengaruh Protokol Kesehatan terhadap Keputusan Menginap.

Variabel Protokol kesehatan berpengaruh positif dan signifikan terhadap keputusan menginap. hotel menempatkan media informasi terkait ketentuan protokol kesehatan di lokasi yang strategis, manajemen hotel menerapkan protokol kesehatan yang ketat, hotel menyediakan handsanitizer yang cukup di pintu masuk, lobby, front desk, tombol lantai lift, dan area publik lainnya, hotel menjaga kualitas udara di ruangan dalam hotel, dan paparan sinar matahari, serta melakukan disinfektan pada fasilitas - fasiltas hotel yang sering digunakan oleh tamu.

6. Pengaruh Dominan diantara Variabel.

Variabel yang memiliki pengaruh dominan adalah varibel fasilitas $\left(\mathrm{X}_{2}\right)$. Sehingga dapat dinyatakan terkait dengan pertanyaan faktor yang memberikan dampak yang terbesar (dominan) terhadap Keputusan Menginap Di Hotel Pada Saat Pandemi Covid-19 adalah faktor fasilitas

\section{KESIMPULAN}

Kesimpulan penelitian ini adalah sebagai berikut :
a. Promosi, Fasilitas, Lokasi, Protokol kesehatan berpengaruh signifikan

terhadap keputusan menginap di Hotel Royal Jember.;

b. Harga tidak berpengaruh signifikan terhadap keputusan menginap di Hotel Royal Jember.;

c. Fasilitas berpengaruh dominan terhadap keputusan menginap di Hotel Royal Jember.

\section{DAFTAR PUSTAKA}

Anoraga, Pandji. 2004. Manajemen Bisnis, Cetakan Ketiga. Jakarta: Rineka Cipta, Jakarta

Baunsele, Kasim, Bessie. 2018. Jurnal Bisnis \& Manajemen Vol. 10, No. 2, Juli 2018, Hal. 96 - 109

Darsono Agustinus. 2001. Kantor Depan Hotel. PT.Gramedia Widiasarana Indonesia: Jakarta

Handoko T. Hadi. 2000. Manajemen Personalia Dan Sumberdaya Manusia. BPFE: Yogyakarta

https://id.wikipedia.org/wiki/Pandemi COVID -19, ( akses agustus 2020)

https://tirto.id/apakah-yang-dimaksudprotokol-kesehatan-covid-19-f3W3, (akses Nopember 2020)

Katemung, Kojo, Rumokoy.2018. Jurnal EMBA Vol.6 No.2 April 2018. Hal. 978-987

Kotler, Philip.. 2008.Manajemen Pemasaran Jilid I (Edisi ke-13). Erlangga, Jakarta

Mustika Zed, Metode Penelitian Kepustakaan, Jakarta: Yayasan Obor Nasional, 2004

Swastha, Basu dan Irawan. 1997. Manajemen Pemasaran Modern. Edisi kelima, Yogyakarta : Liberty. 
Wahab, Salah. 2005. Tourism Marketing. Jakarta: PT Gramedia.

Yoeti, Oka. 1996. Pemasaran Pariwisata, Bandung : Angkasa Bandung. 